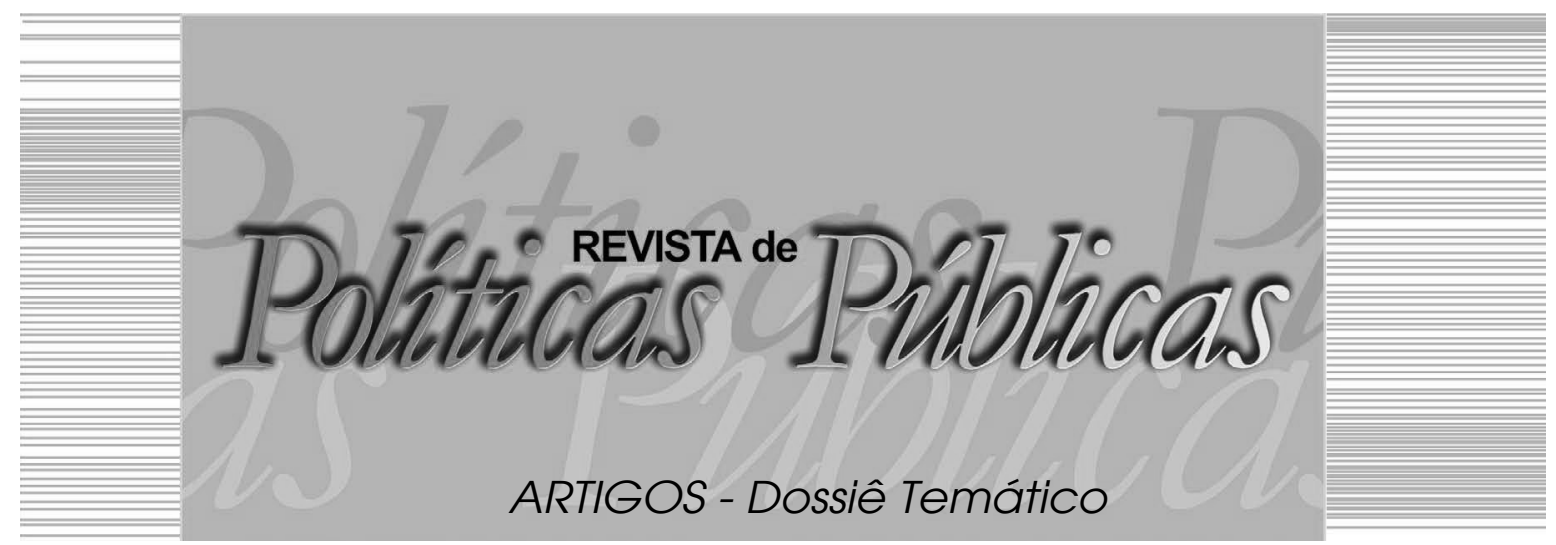

\title{
CONTRARREFORMA TRABALHISTA E PREVIDENCIÁRIA: implicaçÕes para os trabalhadores
}

\author{
Maria Lucia Lopes da Silval \\ Júlio César Lopes de Jesus ${ }^{2}$
}

\section{Resumo}

Este artigo trata da contrarreforma trabalhista (PLC 38/2017) e do movimento de contrarreforma da previdência social em curso desde 1998, sob pressão do capital financeiro, priorizando o seu momento atual sob a face da proposta de emenda constitucional (PEC) n. 287, das propostas de mudanças no modelo de funcionamento e gestão do INSS expressas pelos projetos INSS Digital e Teletrabalho no INSS além da proposta de unificação das bases de dados do SERPRO e da DATAPREV, bem como suas implicações para os trabalhadores. Palavras-chave: Contrarreforma, trabalho, previdência social, INSS, Serviço social.

\section{LABOR AND SOCIAL SECURITY COUNTER-REFORM: implications for workers}

\section{Abstract}

This article deals with the labor counter-reform ( PLC 38/2017) and social security counter-reformation movement happening since 1998, under pressure

Assistente Social, Doutora em Política Social, Professora do Curso de Graduação em Serviço Social e do Mestrado e Doutorado em Política Social da Universidade de Brasília (UnB). Email: lucialopes@unb.br / Universidade de Brasília - UnB: ICC Norte, Mezanino, Campus Darcy Ribeiro, Brasilia- Brasília, DF. CEP: 70000-000.

2 Assistente Social, Doutorando em Política Social pela UnB. Assistente social no Instituto Nacional do Seguro Social (INSS). Email: lopesdejesus25@yahoo.com.br / Instituto Nacional do Seguro Social - INSS: Rua Florianópolis, 349, Siiqueira Campos- Aracaju, SE. CEP: 49075-250. 
from financial capital, prioritizing its present moment under the Constitutional Amendment Proposal (PEC) number 287, proposals for changes in the INSS functioning and management model expressed by the INSS Digital and Telework projects in INSS, in addition to the proposal to unify the SERPRO and DATAPREV databases, as well as their implications for employees.

Key words: Counter-Reform, work, social security, INSS, social work.

\section{INTRODUÇÃO}

Vivem-se tempos sombrios. Direitos são reduzidos, as desigualdades sociais se ampliam, as tensões entre o capital e o trabalho se agudizam e suas relações formalizadas são reorientadas para dar lugar a superexploração. As formas de trabalho parcial, temporário, intermitente, terceirizado, sem garantias e direitos caracterizam a superexploração, explicitando as configurações que o trabalho vem assumindo, desde que a crise do capital se manifestou na década de 1970, e, principalmente, com o seu aprofundamento, a partir de 2008.

No Brasil, ante a crise estrutural do capital e da questionável dívida pública ${ }^{1}$, o Estado vem realizando incessante contrarreforma trabalhista e previdenciária sob pressão do Fundo Monetário Internacional (FMI), do Banco Mundial (BM) e de outras instituições financeiras.

Aqui, usa-se a palavra contrarreforma, para significar, restrição de direitos, na perspectiva de Behring (2003) de recuperar o sentido histórico do termo reforma:

[...] a palavra reforma foi sempre organicamente ligada às lutas dos subalternos para transformar a sociedade e, por conseguinte, assumiu na linguagem política uma conotação claramente progressista e até mesmo de esquerda. O neoliberalismo busca utilizar a seu favor a aura da simpatia que envolve a ideia de "reforma.' [...]Desta maneira, estamos diante da tentativa de modificar o significado da palavra "reforma": o que antes da onda neoliberal queria dizer ampliação dos direitos, proteção social, controle e limitação do mercado etc., significa agora cortes, restrições, supressão desses direitos e desse controle. Estamos diante de uma operação de mistificação ideológica que, infelizmente, tem sido em grande medida bem-sucedida. (COUTINHO, 2010, p. 35, grifo do autor).

No contexto da crise, inicialmente a contrarreforma trabalhista no Brasil tem lugar na reestruturação produtiva, iniciada 
CONTRARREFORMA TRABALHISTA E DA PREVIDÊNCIA SOCIAL:

implicações para os trabalhadores

nos anos 1980 e ganha força, no governo Fernando Henrique, com as privatizações, redução uso do contrato de trabalho por tempo indeterminado, aumento do trabalho parcial e terceirizado, redução de direitos e outros itens já muito discutidos.

No momento, a crise estrutural do capital, cujos efeitos explodem em diversas dimensões é agudizada pela crise política. Esta tem pontos altos no impeachment da Presidenta Dilma Rousseff, em agosto de 2016, na baixíssima popularidade de seu substituto, Michel Temer, acusado de crimes de corrupção e no elevado descrédito popular nas instâncias superiores do legislativo e do Judiciário federal. É nesse contexto, que o projeto neoliberal é recolocado no centro da pauta governamental, pelo governo Temer, ainda que jamais tenha sido abandonado pelos governos Lula e Dilma. Com Temer, ganha magnitude e celeridade. Suas principais marcas são a instituição do novo regime fiscal em dezembro de 2016, a contrarreforma trabalhista aprovada em 11 de julho e promulgada no dia 13 do mesmo mês e a contrarreforma previdenciária em debate. A contrarreforma trabalhista materializou-se, sobretudo, no Projeto de Lei da Câmara (PLC) no 38 de 2017, encaminhado ao Senado Federal $^{2}$, que representa uma catástrofe em relação aos direitos trabalhistas. Modifica cerca de 100 artigos da Consolidação das Leis do Trabalho (CLT) e mais de 200 dispositivos legais que regulam as relações trabalhistas. Antes de sua aprovação, já era visto como "[...] um instrumento de redução [...] da proteção trabalhista, que, se aprovado causará um abalo sísmico sobre os alicerces do direito do trabalho." (ASSOCIAÇÃO NACIONAL DOS PROCURADORES DO TRABALHO et al, 2017, p. 3). A sua aprovação confirma a visão.

No que se refere à previdência social, desde a década de 1990, vem ocorrendo um incessante movimento de contrarreforma, que tem provocado a redução do espaço da previdência pública e a ampliação do espaço da previdência privada. (SILVA, 2012, 2015, 2016). Este movimento não se dissociou da contrarreforma trabalhista em nenhum momento. No governo Temer, ancora-se também no já citado novo regime fiscal que congela investimentos primários em políticas sociais por 20 anos e, sobretudo, na Proposta de Emenda à Constituição (PEC) no 287, de 5 de dezembro de 2016. Para compreender esse movimento é preciso, por um lado, analisálo no contexto da crise em que a acumulação se dá sob regência do capital financeiro, associado a grandes grupos produtivos. 
(CHESNAIS, 2005). Por outro lado, é preciso retomar os anos 1980 quando a seguridade social foi instituída no Brasil pela Constituição Federal (CF) de 1988. Naquele momento, as características da seguridade social e o seu potencial de expansão dos direitos relativos a saúde, previdência e assistência social - conquista do movimento dos trabalhadores em ascenso -, não agradaram ao grande capital, que se move em busca de lucros e vê na mercadorização da saúde e da previdência social públicas, grandes possibilidades para alargálos. Assim, em conjuntura adversa aos trabalhadores, em 1998, por meio da Emenda Constitucional (EC) $\mathrm{n}^{\circ} 20$ este movimento de contrarreforma iniciou-se e mantém-se em curso até o presente. Ora é mais intenso e agressivo, ora mais sutil, a depender de fatores conjunturais e do grau de comprometimento e capacidade de reação dos governos às pressões do capital financeiro. (SILVA, 2016).

A contrarreforma da previdência social tem ocorrido por meio de uma conjugação de medidas restritivas de direitos que ajudam a conformar a chamada política de austeridade fiscal e sustenta a disputa do fundo público, em favor do capital. As medidas que mais chamam a atenção são aquelas que se viabilizam a partir de mudanças na Constituição Federal, porém, a contrarreforma também ocorre por leis ordinárias, decretos ou por decisões gerenciais que assumem a forma de resoluções ou de projetos estratégicos de gestão de órgãos específicos.

Nessa direção, desde agosto de 2016, quando se apropriou da Presidência da República, o governo Temer vem adotando medidas e apresentando propostas que aprofundam a contrarreforma da previdência social, associada à do trabalho. Entre elas, a extinção do Ministério da Previdência Social e Trabalho, com a transferência da competência atinente a previdência social ao Ministério da Fazenda e a operacionalização dos benefícios pelo Instituto Nacional do Seguro Social (INSS), que se encontra vinculado ao Ministério do Desenvolvimento Social (MDS); a PEC no 287/2016 - a mais agressiva proposta de restrição de direitos da história da seguridade social; os projetos intitulados INSS Digital e teletrabalho no INSS, além da proposta de fusão dos bancos de dados do Serviço Federal de Processamento de Dados (SERPRO) e da Empresa de Tecnologia e Informações da Previdência Social (DATAPREV). Este conjunto de medidas e propostas, se forem aprovadas, poderão acarretar 
CONTRARREFORMA TRABALHISTA E DA PREVIDÊNCIA SOCIAL:

implicações para os trabalhadores

prejuízos aos trabalhadores e aprofundar as desigualdades sociais no país. É sobre isso que trata este artigo.

Sua organização compreende esta introdução, uma seção, que constitui o desenvolvimento e intitula-se, aspectos da contrarreforma trabalhista e da previdência social no governo Temer e suas possíveis consequências. Esta seção subdivide-se em três subseções, a contrarreforma trabalhista e possíveis consequência; a contrarreforma da previdência social e possíveis consequências e a terceira, medidas de gestão contrarreformistas atinentes ao trabalho e à previdência social. Ao final, a conclusão.

\section{ASPECTOS DA CONTRARREFORMA TRABALHISTA E DA PREVIDÊNCIA SOCIAL NO GOVERNO TEMER E SUAS POSSÍVEIS CONSEQUÊNCIAS}

A crise do capital manifesta desde o início dos anos 1970, com aprofundamento a partir de 2008, traz consequências diversas para a humanidade. Trata-se de uma crise estrutural do capital prolongada, de difícil solução, que envolve praticamente todos os países do mundo capitalista. (MESZÁROS, 2009). Ao longo das últimas quatro décadas, o capital financeiro firmou-se no comando do conjunto da acumulação, associado a grandes grupos produtivos transnacionais, localizando-se no centro das relações econômicas e sociais. A expansão e força do mercado financeiro, no contexto da crise do capital, alimentou-se da expansão das dívidas públicas dos Estados-Nação que atraiu os fundos líquidos em busca de investimentos financeiros estimulados pelos juros altos. Estes fundos, diante da supervalorização da bolsa, passaram a atuar também no mercado de ações, firmando sua aliança com grandes grupos de empreendimentos produtivos. Isso ocorreu, primeiramente, nos Estados Unidos, desde 1982, mas, posteriormente, também em outros países, como o Brasil, tornando o capital financeiro uma grande potência no capitalismo contemporâneo. Assim, o poder do capital financeiro foi construído sobre o endividamento dos governos. Ele, nos últimos quarenta anos tornou-se "[...] uma força financeira alimentada pela Bolsa." (CHESNAIS, 2005, p. 115). É sob sua pressão que a previdência social e a saúde públicas tem sido mercadorizadas ou melhor, financeirizadas. Pois, a dívida pública provoca grande pressão sobre os Estados-Nação quanto à destinação do fundo público e aos destinos das políticas públicas. Ao tornar- 
se fonte de poder dos fundos de investimentos, pressiona para as privatizações. Foi dessa forma que "[...] 'a dívida do terceiro mundo' foi uma alavanca poderosa que permitiu impor as políticas enérgicas de ajuste estrutural, austeridade fiscal, liberalização e privatização." (CHESNAIS, 2005, p. 67, grifo do autor). Nas últimas décadas são as instituições constitutivas do capital financeiro que determinam a repartição da receita, o ritmo do investimento e até as formas do emprego assalariado. Entre estas instituições encontram-se, os bancos, as sociedades hipotecárias e os investidores institucionais: as seguradoras, os fundos de pensão e as sociedades financeiras de investimento financeiro coletivo (os Fundos Mútuos). Neste contexto, sob três argumentos centrais os direitos trabalhistas e da seguridade vem sendo destruídos nos países capitalistas.

O primeiro argumento são as alegações de altos custos do trabalho, forçando as renúncias fiscais em favor das empresas, reduzindo a participação do capital no custeio da seguridade social e ampliando a dos trabalhadores. De acordo com a Associação Nacional dos Auditores-Fiscais da Receita Federal do Brasil (ANFIP) e Fundação ANFIP de Estudos da Seguridade Social e Tributário (2016, p. 22), “[...] em 2015 o conjunto das renúncias [tributárias] totalizou R \$267,3 bilhões". Quanto ao trabalho, o argumento é usado para reduzir direitos trabalhistas pela precarização do trabalho e assim, reduzir os custos da produção. As formas de trabalho parcial, intermitente, temporário terceirizados são usadas para a redução de tais custos, jogando o ônus para os trabalhadores.

O trabalhador brasileiro conhece os problemas da terceirização e que ela representa apenas lucro para o patrão no fim do mês. Em nada beneficia o trabalhador! O salário de trabalhadores terceirizados é $24 \%$ menor do que o dos empregados formais, segundo o Dieese [...]. A terceirização também provoca desemprego, sendo seu índice de rotatividade no mercado de trabalho quase o dobro dos empregados diretamente contratados (33\% x 64,4\%). Terceirizados trabalham 3 horas a mais por semana, em média, do que contratados diretamente. Com mais trabalhadores fazendo jornadas maiores, deve cair o número de vagas em todos os setores. Se o processo fosse inverso e os terceirizados passassem a trabalhar o mesmo número de horas que os contratados, seriam criadas 882.959 novas vagas de emprego [...]. (ASSOCIAÇÃO NACIONAL DOS PROCURADORES DO TRABALHO et al, 2017, p. 8).

$\mathrm{O}$ envelhecimento populacional e a ideia de crise, criando a imagem de inviabilidade da previdência pública sob o regime 
CONTRARREFORMA TRABALHISTA E DA PREVIDÊNCIA SOCIAL:

implicações para os trabalhadores

de repartição é outro argumento recorrente quanto à previdência social, com impacto também em relação ao trabalho. No Brasil fala-se de um déficit fictício da previdência social. Pois, não existe um orçamento da previdência, mas, um orçamento da seguridade social, o qual, apesar das renúncias tributárias, dos desvios de recursos para outros fins, tem sido superavitário. A ANFIP mostra que em 2015, esse orçamento foi superavitário em $\mathrm{R} \$ 11,2$ bilhões (ASSOCIAÇÃO NACIONAL DOS AUDITORES-FISCAIS DA RECEITA FEDERAL DO BRASIL; FUNDAÇÃO ANFIP DE ESTUDOS DA SEGURIDADE SOCIAL E TRIBUTÁRIO, 2016) ainda que no mesmo ano as renúncias tributárias tenham sido elevadíssimas e os desvios de recursos, por meio da incidência da Desvinculação das Receitas da União (DRU) tenham atingido R 63 bilhões (ASSOCIAÇÃO NACIONAL DOS AUDITORES-FISCAIS DA RECEITA FEDERAL DO BRASIL; FUNDAÇÃO ANFIP DE ESTUDOS DA SEGURIDADE SOCIAL E TRIBUTÁRIO, 2016). Além disso, o Brasil é um país jovem, ainda que os indicadores sociais produzidos pelas instituições governamentais apontem para uma mudança na pirâmide etária, reduzindo a base de jovens e ampliando a faixa de adultos e idosos. No âmbito da contrarreforma trabalhista o argumento do envelhecimento populacional é usado para dizer que as leis trabalhistas precisam ser modernizadas, flexibilizadas, leiam-se os direitos devem ser desregulados, para que a força de trabalho das empresas seja renovada com mais facilidade e maior frequência, o resultado é a perda de direitos, a instabilidade no emprego, demissões justificadas, entre outros.

O terceiro argumento, utilizado para favorecer a contrarreforma previdenciária e trabalhista, é que os investimentos na previdência pública e outras políticas sociais provocam o aumento da dívida pública dos governos e desequilibram os orçamentos. Em 2016, de acordo com a equipe de auditoria cidadã da dívida, $43,94 \%$ do orçamento foram destinados para os juros e amortizações da dívida pública e $22,54 \%$ à previdência social. (AUDITORIA CIDADÃ DA DÍVIDA, 2017). Isso mostra a falácia do argumento. No que tange ao trabalho, o argumento é usado como desincentivo às políticas de emprego e sobretudo, contra a realização de concursos públicos e para forçar as terceirizações.

Estes argumentos ardilosos apenas servem para evidenciar que os determinantes estruturais da contrarreforma trabalhista e 
previdenciária são, na realidade, as pressões do capital. Pressões, por um lado, para reduzir os investimentos em políticas públicas e destinar maior parte do fundo público para os serviços da dívida da qual algumas instituições constitutivas do capital financeiro são credoras, além de reduzir o espaço da previdência pública e ampliar o espaço da previdência privada. Por outro lado, para diminuir os custos da produção pela redução de direitos trabalhistas, como salários, férias, decimo terceiro salário, transferência de responsabilidade para o trabalhador e ampliação dos lucros dos empresários.

A conformação das propostas ajudam a confirmar esta afirmação, como se pode ler a seguir.

\subsection{A contrarreforma trabalhista e possíveis consequências}

A contrarreforma trabalhista traz várias e complexas mudanças por meio do PLC no 38/2017, aprovado pelo Senado Federal dia 11 de julho. Dado ao limite de tamanho deste artigo, apenas algumas serão destacadas. A primeira diz respeito ao previsto no art. $442^{\circ}$-B que possibilita a contratação do autônomo com ou sem exclusividade, de forma contínua ou não sem que este seja considerado empregado, com todas as garantias que a lei prevê. Esta situação certamente levará à demissão de milhares de trabalhadores para que esta figura falseada do autônomo contratado seja forjada. Pois, os autônomos não possuem contrato de trabalho registrado em carteira e não possuem vários direitos previstos no art. $7^{\circ} \mathrm{da}$ $\mathrm{CF}$, como férias, décimo terceiro salário, salário mínimo, jornada máxima de trabalho, entre outros. Além disso, sua aposentadoria segue regras diferenciadas, sem a participação do empregador na contribuição. Com isso, os custos dos patrões serão reduzidos. Outro aspecto gritante do PLC, encontra-se em seu art. $2^{\circ}$ que introduz na Lei $\mathrm{n}^{\circ} 6019$, de 3 de janeiro de 1974, o art. $4^{\circ}$-A com vistas a ampla e irrestrita terceirização das atividades das empresas, o que significa maior exploração dos trabalhadores, pela rotatividade, pela dificuldade de acesso aos direitos e ainda pelos maiores riscos de acidentes e morte, pois as empresas que terceirizam, principalmente as pequenas, não asseguram as mesmas condições de segurança no trabalho que aquelas grandes empresas com quadro de pessoal fixo. A terceirização limita ainda o acesso à previdência social porque a rotatividade é muito grande e dificulta o cumprimento das carências exigidas. 
Uma das propostas mais críticas do PLC diz respeito ao trabalho intermitente que passa a ser permitido por meio da alteração do art. $443^{\circ}$ da CLT. Esta nova modalidade de trabalho para os brasileiros, mas já presente em diversos países do mundo, está definida como o contrato de trabalho no qual a prestação de serviços, com subordinação, não é contínua, ocorrendo com alternância de períodos de prestação de serviços e de inatividade, determinados em horas, dias ou meses, independentemente do tipo de atividade do empregado e do empregador. Nessa modalidade de contrato, o trabalhador só trabalha quando é chamado pela empresa, e só será pago pelo tempo que trabalhar. Assim, não terá garantia de jornada nem de renda mínimas. Ademais, o pagamento de direitos como $13^{\circ}$ salário, férias, Fundo de Garantia por Tempo de Serviço (FGTS) e repouso semanal remunerado será sempre proporcional às horas trabalhadas.

Como se não bastasse a exploração, “[...] impõe-se ao trabalhador o pagamento de multa de $50 \%$ (cinquenta por cento) da remuneração que seria devida, caso, depois de aceita a oferta para o comparecimento ao trabalho, não possa trabalhar." (ASSOCIAÇÃO NACIONAL DOS PROCURADORES DO TRABALHO et al., 2017, p. 11). Ou seja, o trabalhador ficará à disposição do empregador por horas, dias, meses, conforme seja a atividade para a qual foi contratado, porém, se na hora exata, dia, mês, (conforme seja o contrato) que o empregador precisar dele e ele não estiver disponível, pagará por isso, $50 \%$ do que ganharia. É o máximo da exploração. No mesmo nível de precarização e até de risco de vida é a permissão para que mulheres gestantes ou lactantes possam trabalhar em condições insalubres. Tal permissão constitui um completo descaso para com a mulher trabalhadora e os seus filhos. Suas vidas não interessam ao capital, como diz Marx (1988, p. 306):

\footnotetext{
O capital não tem [...] a menor consideração com a saúde e com a vida do trabalhador, a não ser quando a sociedade o compele a respeitá-las. À queixa sobre a degradação física e mental, morte prematura, suplício do trabalho levado até à completa exaustão responde: por que nos atormentarmos com esses sofrimentos, se aumentam nossos lucros?
}

Outro aspecto do PLC n 38/2017 que precisa ser comentado é Teletrabalho. Este está previsto como uma nova exceção ao trabalho controlado e fiscalizado e com limitação de jornada de trabalho, por meio da inclusão do art. $62^{\circ}$ da CLT e acréscimo do inciso III. 
Desse modo, os empregados em regime de teletrabalho não estarão sujeitos ao controle da jornada de trabalho, previsto na CLT para os trabalhos remotos. Isso significa que esses trabalhadores poderão ser levados a trabalhar por metas a serem alcançadas, desse modo, poderá ser exigido deles uma jornada de trabalho superior àquela que cumpririam no local de trabalho ou até superior às 8 horas diárias, 44 semanais, previstas na CF. Além do que, a exigência de metas a serem alcançadas poderá exigir o trabalho em domingos e feriados, à noite, sem direito ao adicional noturno, visto que sua jornada de trabalho não será controlada.

Outro elemento atinente ao teletrabalho nos termos do PLC $n^{\circ}$ 38/2017, decorrente da inclusão de outros artigos na CLT, é a responsabilização do empregado pela aquisição e manutenção dos equipamentos necessários para a realização do trabalho. Assim, transfere-se para o trabalhador os custos do trabalho que seriam de responsabilidade do empregador. Além do que o teletrabalho imporá ao empregado, os cuidados com a segurança no trabalho, já que é ele o responsável pela própria segurança das condições de trabalho em sua casa. $\mathrm{O}$ acesso aos benefícios previdenciários será reduzido, como aqueles decorrentes de acidentes no local de trabalho ou por precária manutenção de equipamentos utilizados no trabalho. Entre outras desvantagens, o isolamento em relação aos demais colegas, a fragilização dos vínculos de solidariedade no trabalho, o que implicará fragilização das lutas e das entidades sindicais.

A contrarreforma trabalhista aprovada dificulta o acesso à justiça por meio de medidas, antes inexistentes. Assim, criam-se formas de exploração absurdas que não poderão ser reclamadas. É, como dizem as entidades de trabalhadores da área do trabalho, "[...] a reforma, na realidade, aumentará os níveis de desemprego, diminuirá a qualidade dos empregos no mercado brasileiro, reduzirá direitos e fomentará o descumprimento da legislação trabalhista e, por fim, aumentará a insegurança jurídica nas relações trabalhistas." (ASSOCIAÇÃO NACIONAL DOS PROCURADORES DO TRABALHO et al., 2017, p. 2). Esta redução de direitos implicará mais desigualdade social, mais exploração sobre o trabalho, menos qualidade de vida para o trabalhador, mais tensão e mortes prematuras. 
CONTRARREFORMA TRABALHISTA E DA PREVIDÊNCIA SOCIAL:

implicações para os trabalhadores

A contrarreforma trabalhista está intrinsecamente vinculada à da previdenciária, uma potencializa a outra e assim, ampliam-se os prejuízos aos trabalhadores.

\subsection{A contrarreforma previdenciária e possíveis consequências}

A primeira proposta de contrarreforma da previdência social do governo Temer foi a extinção do Ministério da Previdência Social e Trabalho transferindo órgãos estratégicos e a competência em matéria de previdência social ao Ministério da Fazenda. Assim, o governo, além deixar a previdência social sem qualquer referência administrativa nacional, deixa explicito que a proteção a ser viabilizada pela previdência estará sujeita ao controle de gastos e prioridades estabelecidas pela Fazenda, bem como o seu tamanho e as funções a serem desempenhadas. Com isso, também se explicitou que cada direito reduzido será moeda de troca com o grande capital, que de fato comandou todo o processo de elaboração da PEC no 287/2016 (BRASIL, 2016) que condensa as principais propostas de contrarreforma da previdência social. Aqui, apenas algumas propostas serão referidas, como proposta originária da PEC $n^{\circ} 287 / 2016$ e em seguida, como proposta definitiva do Substitutivo aprovado em 9 de maio de 2017.

A principalproposta originária da PEC n²87/2016éa exigência de idade mínima de 65 anos e um tempo mínimo de contribuição de 25 anos, para fins de aposentadoria, para homens e mulheres de todos os setores; o valor da aposentadoria correspondente a $51 \%$ da média das remunerações e salários de contribuição, acrescido de $1 \%$ por cada ano de contribuição no momento da aposentadoria. Para se alcançar $100 \%$ da média, deve-se contribuir por 49 anos. Após 5 anos de vigência da PEC haverá o aumento da idade mínima de 65 anos, conforme seja o incremento da esperança de sobrevida após 65 anos de idade, por ano inteiro, estimado pelo Instituto Brasileiro de Geografia e Estatística (IBGE). Outra proposta é a mudança da alíquota de contribuição do trabalhador rural (segurado especial) de $2,1 \%$ sobre a comercialização de seus produtos, valendo para o grupo familiar, para uma alíquota individual sobre o salário mínimo, a ser definida em lei. Em 9 de maio a Comissão Especial destinada a proferir parecer sobre a PEC $n^{\circ}$ 287/2016 aprovou o substitutivo final a ser submetido à votação do plenário da Câmara Federal ${ }^{3}$. Esta conjugação de itens que formam a proposta principal da PEC 
foi assim modificada: a Comissão Especial reduziu a idade mínima para fins de aposentadoria das mulheres urbanas para 62 anos e das mulheres rurais para 57 anos; a idade dos homens urbanos ficou em 65 anos e rurais em 60 anos. A contribuição para os trabalhadores rurais retornou aos 15 anos atuais, porém de modo individual em alíquota de contribuição igual aos trabalhadores urbanos de baixa renda para uma aposentadoria no valor de um salário mínimo. $\mathrm{O}$ valor da aposentadoria para os demais trabalhadores, cumpridos os requisitos de idade mínima e tempo de contribuição, foi sugerido para $70 \%$ da média das contribuições e para se alcançar $100 \%$ da média serão necessários 40 anos de contribuição, pois nos primeiros cincos anos, após o mínimo exigido, cada ano de contribuição corresponderá a $1,5 \%$ da média, no segundo quinquênio, cada ano corresponderá a $2 \%$ e no terceiro quinquênio, a $2,5 \%$. Portanto, nota-se que as diferenças não são tão substanciais. Se aprovadas, as propostas do substitutivo, os prejuízos dos trabalhadores serão enormes.

Em um país tão desigual como o Brasil, essas mudanças, se aprovadas e implementadas, deixarão as camadas de trabalhadores com menores rendimentos sem proteção e empurrarão as camadas de rendas mais elevadas para a previdência complementar - este é o seu maior objetivo. Para muitos trabalhadores as medidas serão um adeus à possibilidade de aposentadoria. Seja pelos níveis elevados de desemprego e rotatividade no trabalho, seja pela insuficiência de renda para contribuir, na condição de desempregados ou ainda por não alcançarem a idade mínima exigida. A esperança de vida no Brasil é muito diferente entre as regiões, sexo e faixa de renda. Sendo que os mais pobres do Norte e do Nordeste brasileiros são os que possuem menor esperança de vida, assim, serão os mais afetados, principalmente os trabalhadores rurais que produzem em regime de economia familiar, que terão que contribuir individualmente para acessarem a uma aposentadoria. Sabe-se da grande informalidade do trabalhado na área rural, da mesma forma que se sabe que a grande maioria dos pequenos produtores, que trabalha em regime de economia familiar não consegue produzir para além do necessário ao seu sustento. Assim, dificilmente poderá comercializar os seus produtos de modo a assegurar recursos suficientes para contribuir, ainda que, com o percentual de $5 \%$ sobre o salário mínimo, como o fazem atualmente os trabalhadores urbanos de baixa renda aos quais foram equiparados. Para estes trabalhadores e estas trabalhadoras 
CONTRARREFORMA TRABALHISTA E DA PREVIDÊNCIA SOCIAL:

implicações para os trabalhadores

rurais, uma alternativa seria o acesso ao Benefício de Prestação Continuada (BPC) da assistência social destinada aos idosos. Todavia, a PEC n $287 / 2016$ também impôs novas regras para acesso a este benefício, elevando a idade mínima de 65 para 70 anos - idade que aumentará, conforme regra geral, após 10 anos de vigência. A PEC também propôs desvinculação do valor do benefício do valor do salário mínimo. O substitutivo, no entanto, manteve esta vinculação ao mínimo e rebaixou a idade mínima para 68 anos. Esta alteração quanto á idade é insignificante, pois ainda é muito superior à média da esperança de vida de homens e mulheres de algumas regiões.

Desse modo, dificilmente trabalhadores e trabalhadoras pobres, principalmente do norte e nordeste alcançarão uma aposentadoria ou o BPC para idosos, a partir das novas regras. Serão definitivamente alijados desse direito, tendo que permanecerem até o final de suas vidas trabalhando para viver ou, se impedidos de trabalhar por alguma limitação, ficarão submetidos a condições degradantes de vida, tendo que suportar a privação do atendimento de suas necessidades básicas. As mulheres serão as mais prejudicadas nessa proposta de contrarreforma, por causa da tentativa da PEC e do substitutivo de igualar o que é diverso. As mulheres continuam exercendo uma jornada de trabalho, muito superior à dos homens, porque a elas é atribuída a maior parte das atividades domésticas e dos cuidados para com crianças, adolescentes e adultos doentes e pessoas idosas da família. Assim, ao invés de reduzir as desigualdades entre homens e mulheres, a contrarreforma ampliará essas desigualdades, se for aprovada.

São muitas as propostas que compõem a PEC no 287/2016, que não se pode analisar aqui dado ao espaço, todavia duas delas, ainda precisam ser comentadas. A primeira diz respeito às regras de transição, que na proposta originária fazia um corte apenas pela idade para quem já estava trabalhando, ou seja, as regras valeriam para os novos contribuintes e para os homens com menos de 50 anos de idade e as mulheres com menos de 45 , que já contribuem. Os demais cumpririam transição correspondente ao tempo restante de contribuição mais $50 \%$ sobre ele. A segunda diz respeito a proposta originária de proibição de criação de novos Regimes Próprios de Previdência Social (RPPS) pelos estados e municípios, os que mantiverem o regime devem fixar o teto do Regime Geral de Previdência Social (RGPS) para a aposentadoria e criar a previdência 
complementar. Em relação à primeira situação, a transição para o novo regime, o substitutivo criou uma escala móvel de idade, fazendo uma diferença entre trabalhadores vinculados ao RGPS e os servidores públicos vinculados aos RPPS. Para os que se vinculam ao RGPS, a idade de partida será 53 anos se mulher e 55 se homem. Para os servidores públicos, a idade de partida será 55 anos para mulheres e 60 anos para os homens. Em relação à segunda situação, o substitutivo traz a possibilidade de contratação pelo Estado de entidades de previdência complementar privada, que não tenham sido criadas exclusivamente para atender aos servidores públicos. Estas duas proposições eliminam qualquer dúvida quanto aos propósitos fundamentais da proposta de contrarreforma de atender aos interesses dos fundos de pensão e outras instituições constitutivas do capital financeiro. As regras de transição endurecidas para os servidores públicos, deve-se ao fato de estes servidores possuírem salários mais elevados e, diante dos grandes prejuízos mais facilmente buscarão os fundos de pensão para complementarem os valores de suas aposentadorias, algumas delas já condicionadas ao valor do teto dos benefícios do RGPS, atualmente correspondente a $\mathrm{R} \$ 5.531,00$. A outra medida incluída pelo substitutivo do relator, de contratação de entidades privadas de previdência para os servidores públicos, que não tenham sido criados para este fim, é o mais explícito e descarado favorecimento ao capital financeiro que ficará gravado na $\mathrm{CF}$, no caso de as propostas serem aprovadas. Espera-se que este ataque brutal contra os trabalhadores brasileiro não seja concretizado. Que as lutas dos trabalhadores em curso possam impedi-lo.

\subsection{As medidas de gestão contrarreformistas atinentes ao trabalho e à previdência social}

Como foi anunciado, outras medidas de cunho gerencial ou administrativo estão sendo processadas na perspectiva de reforçar a contrarreforma previdenciária e trabalhista. Algumas delas estão sendo desenvolvidas e executadas no âmbito do INSS que realiza o reconhecimento de direitos aos benefícios administrados pela previdência social, como é o caso do projeto INSS Digital, uma estratégia de atendimento remoto que amplia os atendimentos remotos que já realizados pelo instituto e ao mesmo tempo, prepara a autarquia e os seus servidores para o teletrabalho. Estas medidas serão ligeiramente comentadas nesta subseção, com a intenção de mostrar suas relações com as medidas e proposições de contrarreforma 
CONTRARREFORMA TRABALHISTA E DA PREVIDÊNCIA SOCIAL:

implicações para os trabalhadores

determinadas legal ou constitucionalmente. Outras medidas estão sendo realizadas fora do INSS, como é o caso da proposta de unificação das bases de dados do SERPRO e da DATAPREV. Pelo visto, esta última, é pouco conhecida, embora tenha sido aventada desde o governo Dilma, quando muitas especulações foram feitas e divulgadas pelos jornais e redes sociais. A maior parte, referia-se aos possíveis ganhos que esta fusão poderia oferecer ao mercado. Uma das especulações difundida, ainda em 2015, foi da Telecomunicações Brasileiras S. A. (TELEBRAS) gerir esta fusão, como forma de obter ganhos junto ao governo e ao mercado, como a valorização de suas ações por meio do interesse que o controle desta fusão despertaria no mercado financeiro em decorrência das informações cadastrais de milhões de assalariados (SERPRO), aposentados e pensionistas do RGPS (DATAPREV). É o que diz o site aposentelecon:

\begin{abstract}
Segundo os técnicos, num ambiente em que a Telebras - uma empresa com o capital aberto na Bovespa - absorva o Serpro e a Dataprev, isto poderia interessar a novos investidores do mercado financeiro. Para tanto, alegam que o benefício da medida seria a "possibilidade de realizar oferta secundária de ações, minimizando a necessidade de aportes da União." (TIC..., 2015, grifo do autor).
\end{abstract}

Atualmente, volta-se a falar sobre o assunto, gerando especulação e insegurança aos servidores dos órgãos e preocupação das entidades sindicais.

Aqui, vale registrar, que diante das especulações, a Federação Nacional dos Sindicatos dos Trabalhadores em Saúde, Trabalho, Previdência e Assistência Social (FENASPS), por meio do Oficio n ${ }^{\circ}$ 006, de 10 de janeiro de 2017 dirigiu-se ao Presidente do INSS para manifestar-se e obter informações sobre o assunto:

Embora a notícia de que a [...] DATAPREV e o SERPRO [...] vão ser unificados esteja circulando há muito tempo, os funcionários do setor de Tecnologia da Informação (TI) de ambas as empresas estão apreensivos porque já estão sendo "tramandas" medidas contra a DATAPREV e o SERPRO.

O objetivo da unificação é ter o controle, num único órgão, de todas as informações dos sistemas fiscais e seguro e seguridade social, que desta forma viabilizará o projeto de implantar o serviço online de benefícios, com o acesso integrado destas informações, que hoje são colhidas mediante convênio entre a Receita Federal, o Ministério do Trabalho e o INSS. 
[...] na realidade estão desmontando totalmente o sistema de previdência e seguridade social e vão leiloar pelo melhor ou menor preço o gigante banco de dados da previdência e do Serpro. [...]

Com isso posto solicitamos mais informações sobre a unificação da DATAPREV com o SERPRO. (FEDERAÇÃO NACIONAL DOS SINDICATOS DOS TRABALHADORES EM SAÚDE, TRABALHO, PREVIDÊNCIA E ASSISTÊNCIA SOCIAL, 2017a, p. 1-2, grifo do autor).

Em 17 de abril de 2017, a DATAPREV noticiou em seu portal que o presidente da autarquia havia reunido com a presidente do SERPRO para tratarem da possibilidade de compartilhar tecnologias, sem qualquer referência à uma possível fusão dos órgãos:

O presidente da Dataprev, André Leandro Magalhães, reuniu-se na quinta-feira (13/4) com diretora-presidente do Serpro, Glória Guimarães, para tratar da possibilidade de compartilhamento da experiência entre as duas empresas. O encontro aconteceu na sede do Serpro. André Magalhães mencionou a expertise de décadas na prestação de serviços à sociedade brasileira, tanto do Serpro quanto da Dataprev. "Nós conhecemos o serviço público, estivemos presentes ontem, hoje e continuaremos amanhã, sempre conhecendo o negócio. Daí a importância da defesa do espaço de atuação de nossas empresas", explicou o presidente da Dataprev. já Glória Guimarães lembrou que já existe entre as empresas um compartilhamento na área de infraestrutura, nuvem e prospecção de tecnologias. "Somos instituições complementares e nosso trabalho é muito importante para o país, pois temos um papel relevante no governo digital. Uma [Dataprev] cuida muito do social; a outra, da parte fiscal e econômica e gestão governamental [Serpro]", avaliou. (EMPRESA DE TECNOLOGIA E INFORMAÇÕES DA PREVIDÊNCIA., 2017, grifo do autor).

Todavia, a notícia fala da possibilidade de realização de reuniões mensais, fóruns ou workshop entre as organizações, para discussão de problemas ou novos negócios:

Durante o encontro, que também contou com a presença do diretor de Relacionamento com Clientes do Serpro, André de Cesero, surgiu a ideia de serem realizadas reuniões mensais entre as presidências e diretorias dos dois órgãos. "Buscamos oportunidades para discussão de problemas e novos negócios. Não sabemos ainda o formato, pode ser fórum, workshop", detalhou André Magalhães. [...] segundo o presidente da Dataprev, a ideia é buscar [...] convergência e alinhamento entre as empresas públicas com o objetivo de promover eficiência e efetividade em suas áreas 


\section{CONTRARREFORMA TRABALHISTA E DA PREVIDÊNCIA SOCIAL:}

implicações para os trabalhadores

de atuação. (EMPRESA DE TECNOLOGIA E INFORMAÇÕES DA PREVIDÊNCIA, 2017, grifo do autor).

Diante disso, questiona-se se tais encontros não fazem parte de uma estratégia do governo para unificar tais órgãos, uma vez que na MP no 782, de 30 de maio de 2017, a DATAPREV já não aparece vinculada ao Ministério da Fazenda. Certamente, esta fusão despertará muito o interesse do capital financeiro. $\mathrm{O}$ acesso aos dados sob responsabilidade e guarda destas empresas possibilitará muitas operações, como os empréstimos consignados em folha, já bastante realizados, as poupanças incentivadas e outras operações que, forçam as transferências monetárias de servidores públicos, aposentados e pensionistas, aos bancos e outras instituições financeira, sob o nome de investimentos. A fusão dos órgãos seguiria a mesma lógica, das propostas e medidas de contrarreforma da previdenciária, de favorecimento ao capital.

O projeto INSS Digital surge sob a justificativa de elevar a qualidade do atendimento ao público, enfrentar a redução de pessoal nas Agências da Previdência Social (APS), racionalizar processos e reduzir custos. A projeto teve a experiência Piloto na cidade de Mossoró. Quanto as justificativas, o projeto ressalta:

Uma sondagem de 2016 promovida pelo IBOPE Inteligência [..] revelou que $90 \%$ dos brasileiros entende que os serviços públicos deveriam ter melhor qualidade, dado os elevados impostos dedicados ao seu custeio; e 70\% considera que este déficit de qualidade se deve à má gestão dos recursos disponíveis. [...]. Dentre os órgãos públicos prestadores de atendimento no Brasil, terceiro lugar em baixa qualidade na percepção do cidadão, o [...] INSS é aquele que melhor representa o Governo Federal, em função da dimensão de sua rede de atendimento própria. São 1539 agências de atendimento ao público ativas, 86 agências de atendimento dedicadas a demandas judiciais, 7 agências dedicadas à operacionalização de acordos internacionais, orquestradas por 104 Gerências-Executivas [...] e 5 Superintendências Regionais. [...]. Nesta rede trabalham 35.113 servidores ativos. [...]. No entanto, mesmo com sua estrutura colossal, os tradicionais processos de prestação de serviços da Autarquia não cobrem adequadamente sua demanda de atendimento. Filas de espera do INSS frequentemente figuram nas manchetes de jornais populares, alcançando, por vezes, tempos de espera superiores a um ano. (INSTITUTO NACIONAL DO SEGURO SOCIAL, 2017, p. 16-17). 
No que se refere à deficiência de servidores, o documento destaca que "[...] do total de servidores ativos do quadro funcional mais de 12 mil servidores se encontram em abono de permanência, ou seja, 1/3 dos servidores reúnem condições para pleitear a aposentadoria." (INSTITUTO NACIONAL DO SEGURO SOCIAL, 2017, p. 30), afirmando em seguida, que "[...] diante do quadro de busca de equilibro das contas públicas e a contenção do aumento percentual de gastos com pessoal, não há perspectiva de que essa força de trabalho seja reposta na sua integralidade." (INSTITUTO NACIONAL DO SEGURO SOCIAL, 2017, p. 30). Diante disso, é preciso construir estratégias viáveis para responder às demandas, melhorando a qualidade de atendimento. Assim, a proposta de INSS Digital, é apresentada como a solução dos problemas e "[...] segue a trilha das recentes tendências de prestação de serviços por meio eletrônico, os chamados e-Serviços, e promove a aplicação da tecnologia da informação a implementação colaborativa intersetorial de políticas públicas." (INSTITUTO NACIONAL DO SEGURO SOCIAL, 2017, p. 11).

Em linhas gerais, inicialmente, a proposta, volta-se à implantação do requerimento eletrônico para elevar o volume de atendimento remoto, reduzir o tempo de espera no agendamento, reduzir o tempo de espera para atendimento nas APS, reduzir as demandas judiciais e de ação civil pública e mandados de segurança, além de reduzir $\mathrm{o}$ atendimento presencial ampliar os atendimentos. Para tanto, a estratégia fundamental será a celebração de convênios com sindicatos, associações, empresas, entre outros para que atendam à população requerente de benefícios por meio do requerimento eletrônico e enviem a documentação para ser validada pelo INSS. Posteriormente, o requerente deverá obter uma senha eletrônica para acompanhar o seu processo. (INSTITUTO NACIONAL DO SEGURO SOCIAL, 2017). É importante registrar que a justificativa para a redução de pessoas nas APS aparece no projeto como se fosse uma excelente estratégia ou até uma grande conquista em relação à qualidade do atendimento. É como se a presença do público nas APS fosse indesejada e piorasse as condições de trabalho:

O novo fluxo de trabalho permite a redução da quantidade de pessoas nas Agências da Previdência Social proporcionando assim um ambiente de trabalho mais saudável ao servidor e ao cidadão, que contará com um atendimento personalizado. Com o INSS Digital a análise do requerimento será realizada na retaguarda 
CONTRARREFORMA TRABALHISTA E DA PREVIDÊNCIA SOCIAL:

implicações para os trabalhadores

da APS ou em outra localidade sem a presença do cidadão desta forma as condições de trabalho do servidor que atuar na análise de benefícios, tende a ser melhor que a atual. (INSTITUTO NACIONAL DO SEGURO SOCIAL, 2017, p.28-29).

Tal reflexão parece incompatível com a finalidade da instituição, de viabilizar direitos, que só se realiza pelo atendimento ao público. Nota-se que os erros de gestão e falta de compromisso de gestores e governantes com as condições adequadas de atendimento, sobretudo, com a quantidade suficiente de servidores públicos, bem qualificados e bem remunerados, com as condições de trabalho éticas e técnicas compatíveis com as exigências das demandas profissionais, cujas ausências geram tensões no ambiente de trabalho, são transferidos para a presença das pessoas nas APS. Tais erros e falta de compromisso devem ser denunciados. Não são os segurados que provocam tensão sobre os servidores, mas as condições inadequadas de atendimentos nos termos referidos. Gestores que pensam assim não poderiam gerir instituições como esta de tão grandiosa finalidade. Este projeto é uma forma sutil de expulsão dos segurados do âmbito da APS, é também uma tentativa de colocar os servidores tensos, com sobrecarga de trabalho e desvalorizados profissionalmente contra a população. É ainda uma forma de desqualificar os serviços prestados por transferir para terceiros, chamados parceiros, competências do Estado, que cabe ao INSS realizar.

O pior de tudo é que o projeto está em curso, sem debate suficiente entre os gestores responsáveis por sua implantação e as representações sindicais dos servidores, o que, demonstra o caráter impositivo do governo e dos gestores que o representam no INSS.

O propósito do INSS é que até o final de 2017, cerca de 300 APS já estejam com o projeto INSS Digital implantado. Todavia, a experiência piloto no município de Mossoró, estado do Rio Grande do Norte, já revelou uma gama de problemas identificados pelos representantes da FENASPS, que acompanharam o seu desenvolvimento inicial. Entre os limites identificados, a entidade ressalta (FEDERAÇÃO NACIONAL DOS SINDICATOS DOS TRABALHADORES EM SAÚDE, TRABALHO, PREVIDÊNCIA E ASSISTÊNCIA SOCIAL, 2017b), que a recepção de documentos feita por estagiários, que não possuem conhecimentos técnicos suficientes conduz à montagem dos processos de forma incorreta, gerando exigências e retrabalho aos servidores das APS aos quais cabe a análise dos processos e autenticação dos documento, após a 
digitalização dos mesmos pelas entidades conveniadas. Além disso, a ausência de um limite para a entrada de requerimentos gera uma explosão de agendamentos incompatível com a força de trabalho disponível para analisá-los. O sistema que administra o fluxo de processos vinculado à matricula do servidor apresentou:

\begin{abstract}
Instabilidade; dificuldade para organizar os arquivos na montagem do processo; ausência de recursos para identificar cópias simples de autenticadas; aumento no tempo de análise, motivado pelo congestionamento de programas no mesmo monitor gerando queda de produtividade, desmotivação do servidor e distanciamento entre os servidores da análise e os do atendimento, provocado pela segregação imposta pela parede que divide ao meio a APS e a fixação de metas individuais inatingíveis. (FEDERAÇÃO NACIONAL DOS SINDICATOS DOS TRABALHADORES EM SAÚDE, TRABALHO, PREVIDÊNCIA E ASSISTÊNCIA SOCIAL, 2017b, p. 1).
\end{abstract}

Ademais, segundo a entidade, o excesso de sistemas e o aumento de exposição ao monitor provocaram fadiga visual pela necessidade de alternar telas e sistemas para analisar um processo. E, o ponto mais destaco pelos servidores foi o fato do projeto possuir característica individual de demanda e sua vinculação ao salário do servidor sob a lógica da produtividade: "Os processos digitalizados são vinculados a uma matrícula, gerando sensação de sobrecarga. Mantida a lógica vigente, de produtividade vinculada ao salário, cabe ressaltar que o estoque de processos está diretamente atrelado aos vencimentos do servidor." (FEDERAÇÃO NACIONAL DOS SINDICATOS DOS TRABALHADORES EM SAÚDE, TRABALHO, PREVIDÊNCIA E ASSISTÊNCIA SOCIAL, 2017b, p. 1).

Além do identificado pela FENASPS, a análise do projeto como um todo, revela:

- Disfarce na origem de sua implantação

- A escolha da Gerência Executiva do INSS em Mossoró (RN) para a experiência piloto foi justificada por ser Mossoró uma cidade de médio porte e pela gerência demonstrar bons indicadores institucionais. Mas, sua condição é muito diversa da condição da maioria das demais gerências que sofre a falta de pessoal e de equipamentos, possui sistemas instáveis para consultas de dados etc. Assim, sua escolha pode mascarar a capacidade real do projeto. 
CONTRARREFORMA TRABALHISTA E DA PREVIDÊNCIA SOCIAL:

implicações para os trabalhadores

- Manutenção das filas virtuais e dos processos burocráticoinstitucionais

- Uma segunda questão importante refere-se ao site interativo criado no primeiro semestre de 2017, denominado de $\mathrm{Meu}$ INSS. Este instrumento de comunicação entre o INSS e os segurados da previdência social e suas representações integra o projeto INSS Digital. O novo é a possibilidade dos que procuram os serviços do INSS enviarem com antecedência os documentos necessários para requererem um benefício. Todavia, isso não significa que tais documentos serão analisados com antecedência pelos servidores do órgão, pois estes possuem uma lista de prioridades de atendimento. Além disso, a primeira análise pública comparativa entre os meses de fevereiro e abril de 2016 e fevereiro e abril de 2017, antes e depois do INSS digital, quanto ao número de requerimento por espécie de benefícios mostra uma redução destes, exceto quanto à aposentadoria especial, que houve um pequeno aumento; o número de concessões praticamente se repetiu; houve "[...] aumento no número de concessões decorrentes de ações judiciais de $7,8 \%$ antes do piloto para $13 \%$ depois da implantação do INSS Digital" (ALVES, 2017). Assim, as filas virtuais continuam, o projeto já nasce sem sucesso neste item.

- Precarização do atendimento nas agências e retrabalho no INSS

Os segurados continuaram a se deslocar até uma APS para levar documentos que deverão ser autenticados e validados por um servidor habilitado para esta tarefa, após sua digitalização por um estagiário. Caso haja pendências, terão que voltar outro dia para cumpri-las, tendo que se submeter aos mesmos procedimentos. Portanto, além do estresse dos segurados terem que se dirigir a dois lugares (local do conveniado eà APS). Assim, o fluxo tende a provocar muito retrabalho aos servidores, a tornar-se mais burocrático do que os fluxos anteriores. Pode também estimular as aposentadorias dos servidores que já reúnem as condições para isso, o que poderá reduzir drasticamente o número de servidores nas agências diante do quadro e da contrarreforma trabalhista em curso, a exemplo das propostas do Teletrabalho. 
- Esvaziamento das funções do INSS e repasse de suas responsabilidades

O projeto transfere para prefeituras, sindicatos e cooperativas, empresas entre outros conveniados, parte das suas responsabilidades. Assim, as funções do INSS serão esvaziadas sem que os objetivos anunciados sejam alcançados. Por exemplo, o projeto prevê que o trabalhador rural sequer precisaria ir à agência do INSS para resolver demandas burocráticas e que sua relação seria estabelecida exclusivamente com o seu sindicato e não mais com o INSS. Todavia, esta afirmação não se sustenta, haja vista a necessidade do requerente - no caso, o trabalhador rural - ter que comparecer a uma agência do INSS para poder prestar informações durante o procedimento da chamada entrevista rural. Esta é mais uma razão para se refletir, se o projeto não contribuirá apenas para reforçar o desmonte da estrutura previdência social.

- Aumento do desemprego no país

No caso de implantação da proposta em $100 \%$ das gerências o projeto contribuirá com o aumento do desemprego no país, já que o governo pretende não renovar os contratos com as Centrais 135 (três polos, localizados nos estados da Bahia, Pernambuco e Minas Gerais) ou PrevFone, ocasionando a demissão de milhares de trabalhadores que hoje atuam nesta atividade Além da não renovação da força de trabalho necessária nas APS.

- Cerceamento do acesso à informação e desrespeito às particularidades do país

Muitos trabalhadores serão prejudicados pela imposição do acesso exclusivo à previdência social pelos canais virtuais. $\mathrm{O}$ projeto desconsidera que, no Brasil, até 2015, ainda se tinha que conviver com uma realidade em que cerca de 12,9 milhões de brasileiros não eram alfabetizados, dentre os quais pouco mais da metade deles $(6,5$ milhões) eram idosos com mais de 60 anos de idade (INSTITUTO BRASILEIRO DE GEOGRAFIA E ESTATÍSTICA, 2016). Além do que são muitos os que não possuem computadores em seus domicílios nem acesso à internet. As regiões norte e nordeste, mais uma vez serão as mais prejudicadas. $\mathrm{O}$ acesso às informações, os agendamentos, os recursos, os resultados e demais procedimentos pela internet, enquanto uma opção a mais para os trabalhadores que possuem a proteção social da previdência é algo importante. Porém, 
CONTRARREFORMA TRABALHISTA E DA PREVIDÊNCIA SOCIAL:

implicações para os trabalhadores

quando esta opção passa a ser a única alternativa, torna-se excludente e limitador de direitos.

A análise do projeto revela que um dos seus propósito é testar sistema com vistas ao teletrabalho no INSS (2017, p. 72): "Por fim, o sistema gerenciador de tarefas, parte do presente trabalho, viabiliza a implantação do teletrabalho ou home office no âmbito do INSS”. Revelando, assim, mais uma intrínseca relação do projeto com as contrarreformas trabalhista e previdenciária, previstas, respectivamente, na PEC nº 287/2016 e no PLC no 38/2017.

Assim, o projeto de Teletrabalho no INSS ganha corpo na instituição com a Portaria $\mathrm{n}^{\circ} 1.425 / \mathrm{INSS}$, de 12 de novembro de 2016, a qual institui um Grupo de Trabalho (GT) no âmbito interno para tratar do assunto, cuja composição é exclusivamente de gestores e também com o projeto INSS Digital, como o seu precursor. O teletrabalho poderá tornar o trabalho no INSS mais preconizado ainda, além de impor muitos prejuízos aos trabalhadores, seja pela elevação de metas a serem cumpridas; repasse dos custos com as condições de trabalho aos servidores; pela elevação da jornada de trabalho e redução do tempo dedicado à família; fragilização da carreira e da organização dos trabalhadores, entre outros.

\section{CONCLUSÃO}

A contrarreforma trabalhista e previdenciária em curso no Brasil caracterizam-se como verdadeiros vendavais destruidores de direitos conquistados ao longo dos anos pelos trabalhadores. Suas implementações imporão prejuízos enormes aos trabalhadores enquanto os empresários e instituições constitutivas do capital financeiro serão beneficiados. As medidas ditas gerenciais, como o projeto de junção da DATAPREV e SERPRO, o projeto INSS Digital e o Teletrabalho no INSS são faces da mesma moeda. Assim, mais do que nunca, urge que a classe trabalhadora reaja a estas imposições. As duas greves gerais realizadas no país em 2017 e as diversas outras formas de resistência contra estas medidas expressam a compreensão política dos trabalhadores sobre os prejuízos que poderão sofrer. A luta é o único caminho da vitória.

\section{REFERÊNCIAS}

ALVES, T. S. Acompanhamento do Projeto Piloto do INSS Digital - APS Mossoró. Mossoró, jun. 2017. Texto para debate. Disponível em:<https:// 
drive.google.com/file/d/0B6gKZ4EM6olfbkF5VUY4SGFNdmc/ view?usp=sharing $>$. Acesso em: 17 jul. 2017.

ASSOCIAÇÃO NACIONAL DOS AUDITORES-FISCAIS DA RECEITA FEDERAL DO BRASIL; FUNDAÇÃO ANFIP DE ESTUDOS DA SEGURIDADE SOCIAL E TRIBUTÁRIO. Análise da Seguridade social 2015. 16. ed. Brasília, DF, jul.2016.

ASSOCIAÇÃO NACIONAL DOS PROCURADORES DO

TRABALHO et al. Nota Técnica conjunta PLC 38/2017 - Reforma Trabalhista. Brasília, DF, 2017. Disponível:https://www.diap.org. br/images/stories/Nota\%20tecnica\%20Conjunta\%20Reforma\%20 Trabalhista\%20-\%20Versao\%20final.pdf>. Acesso em: 25 jun. 2017.

AUDITORIA CIDADÃ DA DÍVIDA. Consulta nacional sobre reformas e auditoria da dívida. Brasília, DF, 2017. Disponível em:<http://www.auditoriacidada.org.br/blog/2017/05/31/panfletoexplicativo-consulta-nacional/>. Acesso em: 30 jun. 2017.

BEHRING, E. Brasil em Contra-Reforma: desestruturação do Estado e perda de direitos. São Paulo: Cortez, 2003.

BRASIL. Câmara dos Deputados. Proposta de Emenda à Constituição $\mathrm{n}^{\circ} 287$, de 5 de dezembro de 2016. Brasília, DF, 2016. Disponivel em:<http://static.congressoemfoco.uol.com.br/2016/12/PEC-287-2016. pdf>. Acesso em: 6 abr. 2017.

CHESNAIS, F. A finança mundializada. São Paulo: Boitempo, 2005.

COUTINHO, C. A hegemonia da pequena política. In: OLIVEIRA, F; BRAGA, R.; RIZEC, C. (Orgs). Hegemonia às avessas: economia, política, na era da servidão financeira. São Paulo: Boitempo, 2010. p. 29-43.

EMPRESA DE TECNOLOGIA E INFORMAÇÕES DA

PREVIDÊNCIA. Dataprev e Serpro estudam possibilidade de compartilhar tecnologias. Brasília, DF, 2017. Disponível em:<http:// portal.dataprev.gov.br/dataprev-e-serpro-estudam-possibilidade-decompartilhar-tecnologias>. Acesso em: 30 jun. 2017.

FEDERAÇÃO NACIONAL DOS SINDICATOS DOS TRABALHADORES EM SAÚDE, TRABALHO, PREVIDÊNCIA E ASSISTÊNCIA SOCIAL. Oficio ${ }^{\circ}$ 006, de 10 de janeiro de 2017. Brasília, DF, 2017a. Disponivel em: http://www.fenasps.org.br/images/ stories/pdf/of.fenasps-06.2017_unifica_dataprev.serpro.pdf. Acesso em: 2 jul. 2017. 
CONTRARREFORMA TRABALHISTA E DA PREVIDÊNCIA SOCIAL:

implicações para os trabalhadores

. Relatório FENASPS sobre o projeto-piloto INSS Digital. Brasília, DF, 2017b. Disponível em:<http://www.fenasps.org.br/images/ stories/pdf/rela.comiss.proj.inss.digital_27.03.17.pdf $>$. Acesso em: 2 jul. 2017.

INSTITUTO BRASILEIRO DE GEOGRAFIA E ESTATÍSTICA. Pesquisa nacional por amostra de domicílios: síntese de indicadores. Rio de Janeiro, 2016. Disponível em:<http://biblioteca.ibge.gov.br/ visualizacao/livros/liv98887.pdf >. Acesso em: 3 jun. 2017.

INSTITUTO NACIONAL DO SEGURO SOCIAL. Projeto INSS Digital: uma nova forma de atender. Brasília, DF, 2017.

MARX, K. O Capital. Tradução: Reginaldo Sant'anna. 12. ed. Rio de Janeiro: Bertrand Brasil, 1988a. Livro 1, v. I.

MESZÁROS, I. A crise estrutural do capital. Tradução: Francisco Raul Cornejo et al. São Paulo: Boitempo, 2009.

SILVA, M. L. L. da. Crise, trabalho e "financeirização" da previdência social na Itália e no Brasil. SER Social, Brasília, DF, v. 18, n. 39, p. 407443, jul./dez. 2016.

Previdência Social no Brasil: (dês) estruturação do trabalho e condições para a sua universalização. São Paulo: Cortez, 2012.

Trabalho e previdência social no Brasil no contexto da crise do capital. O Ser Social em Questão, Rio de Janeiro, v. 18, n. 34, p. 137160, jul./dez 2015.

TIC: Telebras incorporando Serpro e Dataprev poderia atrair investidor para nova empresa de TI e Telecom, afirma estudo da DEST. Blog Aposentelecom, 2015. Disponível em:<http://aposentelecom. blogspot.com.br/2015/12/tic-telebras-incorporando-serpro-e.html>. Acesso em: 30 jun. 2017.

\section{Notas}

${ }^{1}$ Tem-se por ilegítima esta dívida pública pela falta de transparência nas transações financeiras entre credores e os governos, pelos elevadíssimos juros, que potencializam o seu valor e comprometem o orçamento público com os seus serviços e amortizações inibindo os investimentos em políticas e serviços essenciais à população.

${ }^{2}$ Em 23 dezembro de 2016, o Executivo encaminhou ao Congresso o Projeto de Lei (PL) autuado como PLC n ${ }^{\circ} 6787$ de 2016 que foi aprovado na Câmara dos Deputados no mês de abril, como Projeto de Lei $n^{\circ} 6878 / 2016$ e desde então, o governo empenhou-se em aprová-lo no Senado, sem alterações, como PLC n 38/2017. No dia 28 de junho a Comissão de Constituição e Justiça (CCJ) do Senado, com composta em sua maioria pela base governamental, o aprovou sem qualquer alteração. Todas as proposições do Senado foram rejeitadas. A aprovação definitiva no plenário do Senado foi em 11 de julho, sem qualquer 
alteração. O Presidente a sancionou dia 13 de julho e terá 119 dias para elaborar a Medida Provisória (MP) e encaminhá-la ao Congresso com as alterações que pretender realizar.

${ }^{3}$ O Relatório definitivo da PEC no 287/2016 foi aprovado pela Comissão Especial em 03 de maio de 2017 e o parecer do Relator foi encaminhado para publicação no dia 9 de maio. Assim, a PEC encontra-se no momento pronta para votação no Plenário da câmara. Informações disponíveis no site da Câmara dos Deputados (Disponível em:<http://www. camara.gov.br/proposicoesWeb/fichadetramitacao?idProposicao=2119881 >. Acesso em: 24 jun. 2017) 